\title{
"Os nossos bugres": As expedições de Hermano Ribeiro da Silva ao Brasil central e a questão indígena
}

\section{"Our Bugres": Hermano Ribeiro da Silva's Expeditions to Central Brazil and the Indigenous Issue}

\author{
Cíntia Régia Rodrigues ${ }^{*}$ \\ Luciana Murari* $^{* *}$
}

\begin{abstract}
Resumo
Este artigo analisa os posicionamentos intelectuais, políticos e ideológicos assumidos pelo sertanista e escritor Hermano Ribeiro da Silva sobre a questão indígena, a partir dos relatos produzidos por ele e por seus companheiros sobre suas incursões ao Brasil central. Esses textos são analisados a partir de três perspectivas. A primeira delas diz respeito à posição dos indígenas em face da sociedade moderna, considerando os fundamentos intelectuais do autor. A segunda explora as experiências de contato vividas durante suas viagens à região, avaliando seu convívio direto com indígenas catequizados e sua tentativa de aproximação com os xavantes, ainda recalcitrantes quanto à aproximação de elementos externos. A terceira analisa as posições do viajante a respeito da atuação de missionários religiosos e das entidades estatais voltadas à dita "civilização" do indígena.
\end{abstract}

Palavras-chave: Brasil central; povos indígenas; relatos de viagem; política indigenista; missões religiosas.

This article analyses the intellectual, political and ideological views of the explorer Hermano Ribeiro da Silva on indigenous issues. It is based on his and his collaborators' accounts about the team's expeditions to central Brazil. These texts are analysed from three perspectives. Firstly, the position of the indigenous people in the modern society, considering the author's intellectual

\footnotetext{
*Doutora em História pela Universidade do Vale do Rio dos Sinos (UNISINOS), professora do Departamento de História e Geografia e do Programa de Pós-Graduação em Educação (PPGE) da Universidade Regional de Blumenau (FURB).E-mail: crrodrigues@furb.br.

** Doutora em História pela Universidade de São Paulo (USP), professora adjunta da Escola de Humanidades e do Programa de Pós-graduação em História da Pontifícia Universidade Católica do Rio Grande do Sul (PUCRS).E-mail: luciana.murari@pucrs.br. Financiamento: Bolsa de produtividade em Pesquisa do Conselho Nacional de Desenvolvimento Científico e Tecnológico (CNPq).
} 
formation. Secondly, it explores the team's contact with the native population, and it assesses their direct contact with those that were catechized and their attempts to approach the Xavantes tribe, who were wary of strangers. Thirdly, it analyses the views of the explorer regarding the role of missionaries and official entities focused on the so-called "civilization" of indigenous peoples.

Keywords: Central Brazil; indigenous peoples; travel reports; indigenous peoples' policy; Christian missions.

Em 1935, o nome do paulista Hermano Ribeiro da Silva ${ }^{1}$ difundiu-se entre o público leitor brasileiro com o lançamento de Nos sertões do Araguaia: narrativas da expedição ás glebas barbaras do Brasil central. ${ }^{2}$ Esse livro narrava sua viagem ao sertão goiano realizada em 1932, com propósitos de exploração territorial. A boa acolhida dessa narrativa encorajou o autor a publicar no ano seguinte o relato de viagens efetuadas entre 1930 e 1931, Garimpos de Mato Grosso: viagens ao sul do Estado e ao lendario Rio das Garças. Essas primeiras iniciativas dirigiam-se às célebres minas de diamante da região. Mais tarde, em 1937, já celebrizado como sertanista, ele organizou uma expedição mais ambiciosa, a "Bandeira Anhanguera", em busca de devassar o território à margem esquerda do rio das Mortes e ascender à serra do Roncador, feito tido como inédito.

Nos dois livros que publicou, o jornalista compartilhou suas experiências e discorreu sobre diversos aspectos geográficos, sociais e econômicos das regiões visitadas, demonstrando uma curiosidade particular em relação às tribos indígenas com as quais havia travado contato, ou seja, "os nossos bugres"', na expressão do autor. A aprovação do público leitor e a generosa distribuição da obra de Hermano - inclusive como livro referendado pelas instituições de Estado, ao ser adquirido para as bibliotecas de escolas públicas

\footnotetext{
${ }^{1}$ Hermano Ribeiro da Silva nasceu na fazenda Santa Adelaide, em Ribeirão Preto, em 2 de setembro de 1902, e se definia como descendente dos primeiros povoadores de São Paulo. Trabalhou como jornalista no Correio Paulistano, e teve algumas de suas viagens patrocinadas pelo jornal Diário Popular. Faleceu em 24 de novembro de 1937, acometido de malária, quando sua expedição batizada como "Bandeira Anhanguera" iniciava seu retorno a São Paulo.

${ }^{2}$ Optamos nesse artigo por manter, nas citações diretas, a ortografia da edição consultada.

${ }^{3}$ O termo "bugre", utilizado várias vezes pelo narrador, era de uso corrente, denominando grupos indígenas de diversas regióes do Brasil, geralmente aqueles tidos como "indolentes" e mais resistentes a projetos de ocupação de seus territórios. O termo origina-se do francês "bougre", registrado no século XII, significando "herético", a partir do latim medieval "bulgàrus", do século VI. Dicionário Houaiss da língua portuguesa. Rio de Janeiro: Objetiva, 2009, p. 336.
} 
- demonstra que essas ideias foram disseminadas entre a elite brasileira de cultura mediana e inespecífica. Iniciativas como a da expedição liderada por ele faziam parte de um movimento de aventureiros, empreendedores, garimpeiros, missionários, cientistas, caçadores e exploradores, brasileiros e estrangeiros, que acorriam ao Brasil central na década de 1930.

Nesse artigo, analisaremos os relatos de viagem publicados por Hermano em 1935 e 1936, as notícias enviadas por ele e as memórias de alguns dos participantes da Bandeira Anhanguera. Assim, buscamos compreender as ideias que governaram os juízos do autor a respeito dos nativos e das iniciativas de cristianizá-los, e ao mesmo tempo avaliar as práticas e vivências de contato experimentadas a partir de suas iniciativas.

\section{A "lei fatal a que se vêm submetendo as raças atrasadas": história e etnografia}

Os relatos de viagem de Hermano Ribeiro da Silva da Silva, jornalista convertido ao sertanismo, ressoaram em um contexto caracterizado por exacerbado nacionalismo, em que se difundia o discurso da necessária incorporação de todo o território e de todas as populações do país à institucionalidade do Estado nacional. Entre essas, as tribos autóctones eram objeto de particular interesse. Ao longo de seus dois livros, ele relatou contatos e teceu considerações sobre diversas etnias - Carajás, Javaés, Bororós, Xavantes, Tapirapés e Caiapós - embora em diversas passagens não tenha chegado a identificar a origem dos indígenas sobre os quais discorria. No relato de sua viagem ao Mato Grosso, a primeira observação a respeito do convívio dos nativos com a sociedade sertaneja identifica um processo de degradação em face de seu passado guerreiro, visto ainda sob as lentes do indianismo romântico. $O$ autor discorre sobre a condição em que restavam os remanescentes selvícolas ao sul do estado, ao observar seus ranchos:

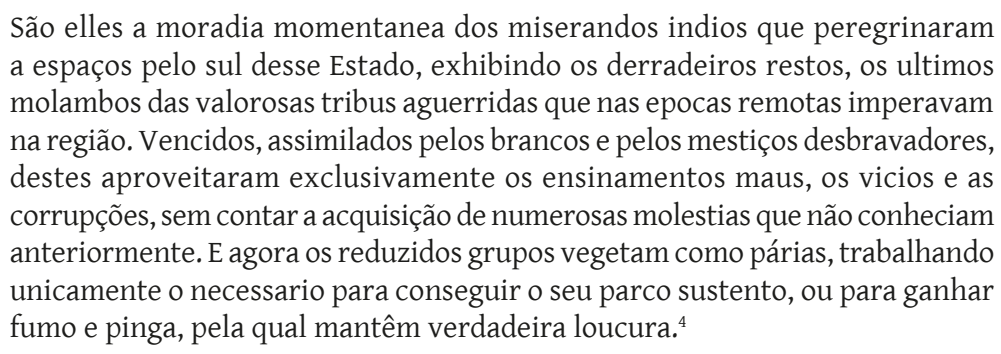

${ }^{4}$ SILVA, Hermano Ribeiro da. Garimpos de Mato Grosso. (Viagens ao sul do Estado e ao lendario Rio das Garças). São Paulo: J. Fagundes, 1936, p. 68. 
O resultado, portanto, de sua inserção na história brasileira havia sido, na visão do viajante, a marginalização social, que os mantinha como alvos preferenciais dos sertanejos, uma vez que, na interpretação do autor, nos sertões não havia ainda sido encerrada a disputa entre "invasores" e "invadidos". Na definição de um membro da elite local, "índio não é gente". Buscando sua sobrevivência, empregavam-se na agricultura, e assim se tornavam vítimas fáceis dos proprietários, muitos deles mestiços indígenas. Em outro trecho do livro, a observação das ruínas do chamado sítio da Contenda, destruído pela luta aguerrida das tribos bororos contra a invasão de suas terras no final do século XIX, demonstra que as marcas da guerra ainda eram historicamente recentes. ${ }^{5}$

Nesse livro, que reporta uma das primeiras viagens de Hermano, suas motivações predominantes eram direcionadas à busca da sorte na mineração. Ainda assim, a curiosidade pela questão indígena manifesta-se em diversos trechos. Desprovido de formação acadêmica específica, o autor desenvolve, em vários momentos de Garimpos de Mato Grosso, debates sobre temas relativos aos autóctones. Em alguns momentos, apresenta concepções próprias sobre sua cultura, como aquela que conceitua um animal convertido em totem como uma "pueril superstição dos selvagens." ${ }^{1}$ No entanto, a maior parte desses debates é feita através da reprodução de trechos de obras e anotações sorvidas de terceiros. Podemos, assim, observar seu interesse em polêmicas como a da origem do nativo brasileiro e do significado das inscrições rupestres encontradas na serra da Onça. ${ }^{7}$

Em Nos sertões do Araguaia, ao narrar a chegada ao estado de Goiás, o primeiro interesse do narrador está em discutir a origem do topônimo, reminiscência da história da ocupação do território às custas do genocídio indígena. O cronista relata o célebre episódio em que Bartolomeu Bueno da Silva colocou fogo em um prato com aguardente, ameaçando transformar todos os rios em fogo se os nativos não lhe indicassem a origem das pepitas douradas que portavam como adorno. Assim teria nascido o epíteto Anhanguera, que em 1937 emprestaria seu nome à empreitada mais ousada de Hermano. O momento do contato estabelece o marco histórico decisivo: a fundação de uma nova sociedade, em nome da "nossa civilização". Mais de duzentos anos

\footnotetext{
${ }^{5}$ Ibidem, p. 68.

${ }^{6}$ Ibidem, p. 79.

${ }^{7}$ Ibidem, p. 212, 209-210.
} 
depois, encerrados os trabalhos de mineração aurífera, os indígenas haviam desaparecido, deixando apenas a memória alusiva do topônimo "Goiás".8

A passagem do tempo entre os séculos é definida, portanto, como um processo inevitável, com base em uma noção evolucionista ${ }^{9}$ que se identificava, sobretudo, com um darwinismo social difuso, em torno de princípios genéricos dotados de considerável eficácia discursiva. ${ }^{10} \mathrm{O}$ resultado disso é a naturalização do processo histórico, que entra em evidente contradição com a denúncia dos crimes cometidos pelos sertanejos em sua guerra ainda em curso contra os indígenas. "Os sertanejos não gostam dos selvicolas, aos quaes estão ligados pelo sangue proximo, assim como os novos-ricos quanto aos proletarios, de cuja classe são egressos", escreve o autor. ${ }^{11}$ As muitas críticas do viajante à sociedade do interior goiano, atrasada e violenta, não eliminam a percepção de seu vínculo, mesmo que deficiente, com a sociedade brasileira. O nativo, em comparação, é percebido conforme um déficit civilizacional que pode ser definido, em essência, como um déficit de nacionalidade.

Os indígenas são diversas vezes identificados, na obra de Hermano, por sua suposta infantilidade, em coerência com o evolucionismo intrínseco às ideias do escritor: "perdendo a bellicosidade innata, transformaram-se actualmente os carajás em grandes crianças quasi inoffensivas, para as quaes, todavia, é opportuna a intimidação dos revolveres dos christãos afim de evitar tolices lamentaveis"12. O sertanista mostra-se estranho a qualquer noção de

\footnotetext{
${ }^{8}$ SILVA, Hermano Ribeiro da. Nos sertões do Araguaia. Narrativa da expedição ás glebas barbaras do Brasil central. São Paulo: Cultura brasileira, 1935.p. 37.

${ }^{9}$ Sobre as referências científicas e político-ideológicas incorporadas pelo sertanista em sua análise do universo sertanejo, ver MURARI, Luciana. "As glebas bárbaras do Brasil Central”: os sertões de Mato Grosso e Goiás nas narrativas de viagem de Hermano Ribeiro da Silva, 1935-1936. História, Ciências, Saúde - Manguinhos, Rio de Janeiro, v.27, n. 4, out.-dez. 2020. No prelo.

${ }^{10} \mathrm{O}$ darwinismo social é um conjunto de doutrinas científicas baseadas em princípios teóricos inspirados pelo evolucionismo darwinista e aplicadas a problemáticas sociológicas. A ele se filiaram as teorias do racismo científico surgidas a partir das últimas décadas do século XIX. Essas assimilaram o humano e o social a trajetórias evolutivas similares às das espécies animais, estabelecendo hierarquias com base em capacidades físicas e psíquicas distintas entre indivíduos e grupos, com fundamentação biológica. A generalidade e a inespecificidade dessas ideias converteu-as em uma poderosa ferramenta retórica. HAWKINS, Mike. Social darwinism in European and American thought, 1860-1945 - nature as model and nature as threat. Cambridge: Cambridge University, 1997.

O evolucionismo de base darwinista disputava espaço, no momento em que escrevia Hermano, com a ascensão de paradigmas científicos mais recentes como o neolamarkianismo, que defendia que os organismos eram passíveis de evolução através de seu intercâmbio com o ambiente, podendo essas adaptações ser transmitidas à progênie. BOWLER, Peter J. Evolution: the history of an idea. Berkeley: University of California Press, 2003.

${ }^{11}$ SILVA, 1935, op. cit., p. 41.

${ }^{12}$ Ibidem, p. 105.
} 
relativismo cultural, interpretando a língua indígena, por exemplo, como a "fala esquisita destes entes atrasados (...)". Em relação a ela, o narrador se sente autorizado, em plena década de 1930, a buscar a referência em um sermão do Padre Vieira: “(...) as taes linguas não se ouvem, pois que não se ouvem dellas mais que o sonido e não palavras articuladas e humanas." ${ }^{13}$

O capítulo 13 de Nos sertões do Araguaia é dedicado a fornecer um panorama geral dos chamados "clans selvagens do Brasil", classificados entre aqueles "já no estadio social pacifico, mas absolutamente afastados de qualquer conquista material de progresso" e "outros, indomitos nos esconsos impenetrados, na existencia apenas exiguamente avaliada pelas tropelias que comettem." Na avaliação do jornalista, o conhecimento sobre os autóctones era ainda controverso. Entre os tupis e os guaranis, teriam restado poucos resquícios de tipos puros, e mesmo entre os que viviam em regiões mais remotas haveria uma "lamentavel decadencia que se approxima da definitiva assimilação pelos invasores." ${ }^{14}$ Decadência e assimilação pareciam, logo, indissociáveis.

De fato, embora abominasse os supostos atraso, agressividade e irracionalidade dos indígenas, o escritor guardava ainda, como vimos, uma certa admiração retórica pelas "valorosas tribus aguerridas" do passado. O vale do Araguaia visitado por ele em 1932 e 1937 guardava em seu território populações xavantes que haviam, até então, rejeitado a aproximação com outras etnias, com os sertanejos e com adventícios. Essas populações tornaram-se, em função disso, o objeto da atenção de exploradores e missionários cristãos atraídos pelo ineditismo do contato, alimentando o que Hermano conceituou como um "rico monumento de imaginosas ficções", em função do exíguo conhecimento sobre elas. Com base em interlocutores diversos, ele compila um acervo de informações que acreditava capaz de desfazer as lendas, satisfazendo a "curiosidade do mundo." 15

A primeira das afirmações do autor diz respeito a seu parentesco com os xerentes que habitavam o norte de Goiás, dado que ele acredita comprovado pela semelhança física entre os grupos, ou seja, sua "fortaleza incommum" e sua corpulência, demonstrada por pegadas que seriam duas vezes maiores

\footnotetext{
${ }^{13}$ Ibidem, p. 105. Trecho do "Sermão do Espírito Santo", proferido pelo Padre Antônio Vieira em junho de 1657 em defesa da liberdade dos indígenas, antes da partida de uma grande missão religiosa ao rio Amazonas. VIEIRA, Antônio. "Sermão do Espírito Santo, proferido em São Luís do Maranhão, do Padre Antônio Vieira” (1657). In VIEIRA, Antônio: Sermões. Tomo V. Lisboa: Lello, 1985. p. 399.

${ }^{14}$ SILVA, 1935, op. cit., p. 114.

${ }^{15}$ Ibidem, p. 223.
} 
que aquelas dos carajás. ${ }^{16} \mathrm{~A}$ descrição que se segue compreende aspectos de sua tradição, como a pintura corporal e os artefatos manuais, fazendo suposições como aquela que associa a preferência deles por viver em regiões campestres ao seu medo das "almas de mortos ruins" reunidas na floresta. Em sua explanação, os xavantes não apenas defendiam seu território como, durante as vazantes, dispersavam seus caçadores pelas áreas vizinhas. Segue o trecho que antecede o relato de quatro eventos "que bastam para reconstituir a indole rebelde desses sêres embrutecidos":

Então é que executam as investidas contra carajás e christãos desprevenidos, assaltos jamais verificados sem ser pelo systema de traição, divergindo nesse pormenor de grande copia das demais tribus tapuias bravas, que acomettem em bandos numerosos, annunciando anteriormente, diversas dellas, o inicio das hostilidades. Dizem ainda que aquelles indios são velocissimos nas carreiras, singularidade que lhes permitte alcançar qualquer adversario em fuga. ${ }^{17}$

Vê-se que o viajante não se esforça por desfazer "as imaginosas ficções" que envolviam aquele povo nas cercanias de seu hábitat, sendo os "crimes dos xavantes" uma mostra de sua "visceral animosidade por todos os demais entes humanos." 18

No entanto, no mesmo parágrafo, ele relata que, de acordo com alguns anciãos carajás, "antigamente", durante o estio, era permitido aos guerreiros xerentes trespassar o Araguaia para visitar seus parentes, de forma que a amizade entre os grupos se mantinha. A partir de determinado momento, essas visitas foram proibidas,

allegando já terem convivido com os invasores christãos e que estes vehiculavam as doenças ceifadoras dos indigenas. Desde então a tribu desmembrada se exilou inteiramente e guerreia com tenacidade os que procuram invadir o seu reino. E lá - continuam os gentíos informantes - não se succumbe das molestias dos civilizados, alcançando a velhice com magnifica saude."19

\footnotetext{
${ }^{16}$ De fato, a história contemporânea registra que a sociedade xavante foi bastante impactada pelo contato com o branco, o que resultou em sua divisão definitiva nos primeiros decênios do século XIX. Enquanto o grupo que ficou conhecido como xerente passou a ocupar o vale do rio Tocantins e a estabelecer relações regulares com os adventícios, o grupo que posteriormente recebeu o nome de xavante migrou em direção ao rio Araguaia, fugindo do avanço dos brancos até alcançar sua margem esquerda na segunda metade daquele século, em direção a Mato Grosso. A tribo se dispersou pelo território conquistado para garantir sua soberania e seu acesso a recursos naturais. A luta indígena no coração do Brasil: política indigenista, a Marcha para o Oeste e os índios xavante (1937-1988). Editora Universidade Estadual Paulista (Unesp), 2011, p. 3-9.

${ }^{17}$ SILVA, 1935, op. cit., p. 225.

${ }^{18}$ Ibidem, p. 227.

${ }^{19}$ Ibidem, p. 227.
} 
Ao recorrer a uma narrativa alimentada pelo tom mítico, veicula-se uma imagem dos xavantes que oscila entre aquela do indígena cruel e monstruoso que ataca de maneira desonrosa e sem piedade fora de seu território, e o indígena dotado de racionalidade, capaz de defender a si mesmo e se manter alheio a doenças em direção a uma idealizada velhice hígida. Ao negar acusações de canibalismo feitas à tribo, o autor recorre a seu velho manual de Charles Letourneau ${ }^{20}$ em busca de dados etnográficos que comprovassem que os brancos também haviam incorrido em tal prática ao longo de sua trajetória evolutiva. ${ }^{21}$

Os xavantes restavam, portanto, ainda alheios ao Brasil. Segundo o escritor, os tipos conhecidos como tapuias - jês, aruaques e caraíbas -, mesmo que distribuídos no centro do território para se esconder do ataque dos brancos, sofriam sua pressão, além de serem vitimados pelas dissenções internas de seus subgrupos. A escrita de uma história dos nativos seria obstada, além disso, pela própria precariedade e heterogeneidade de sua cultura: "Mas quem poderá desentranhar a luz esclarecedora das lendas ingenuas, das theogonias esdruxulas, dos costumes rudes, das linguagens agglutinantes - que são infallivelmente alterados e desiguaes entre cada uma das restantes tribus sertanejas?" Conclui-se que a dificuldade de comunicação com o indígena justificava, ao menos em parte, a ausência de uma classificação estrita de suas etnias. Os povos majoritários, os tupis-guarani, formadores de grandes grupos, contrastam com a fragmentação das tribos tapuias, das quais era possível que jamais se chegasse a uma descrição fidedigna, "[p]orque com o andar do tempo os proprios elementos merecedores de fé vão desapparecendo ou se confundindo com uma miscellanea penosa de desvendar." ${ }^{22} \mathrm{~A}$ preleção apela para um descrédito na própria possibilidade de se atingir um conhecimento válido sobre as tribos brasileiras, o que parecia condená-las a vagar fora da história.

\footnotetext{
${ }^{20}$ Trata-se do volume La sociologie d'après l'ethnographie, publicado pela primeira vez em 1892.

${ }^{21}$ Nesse ponto, o autor faz uma irônica referência a outra expedição que então percorria o Araguaia, liderada pelo jornalista Peter Fleming, e que serviu de base para a escrita de seu famoso livro Brazilian Adventure: "Eu me esqueci de mostrar o volume aos companheiros da Missão Inglêza, o que precisamente lhes recordaria as famigeradas attitudes dos ancestraes, abatendo um pouco as suas presumpções ethnicas." Ibid. p. 228. Embora o evolucionismo torne-se veículo de uma visão depreciativa da formação racial brasileira, Hermano mostra-se sempre disposto a rebatê-la, quando manifestada por estrangeiros. Ibidem, p. 228.

${ }^{22}$ Ibid., p. 115.
} 


\section{2. "Semi-selvagens" e "Índios completamente divorciados da nossa civilização": experiências de contato}

Na narrativa de Hermano Ribeiro da Silva, a observação da realidade sertaneja converte os autóctones, na maior parte das vezes, em vítimas da desordem legal e da ausência estatal, não apenas nas regiões mais remotas, mas também nos centros urbanos. Em sua viagem ao Mato Grosso, o sertanista reporta a submissão de indígenas à condição de escravos em duas usinas de açúcar localizadas na própria capital do estado. Não apenas exerciam trabalho não remunerado, como eram mantidos prisioneiros em "senzalas" guardadas por "fascinoros bandidos armados" e submetidos a castigos físicos ${ }^{23}$. Para ele,

força é confessar que o abandono em que persistem os territorios indigenas ha de produzir muitos frutos denegridos como esses, até quando a clarividencia dos empreendimentos progressistas appareça a illuminar melhor os espiritos dos dirigentes de certas rotineiras unidades brasileiras. ${ }^{24}$

Esse registro consternado da violência em direção aos nativos e a crença de que caberia promover iniciativas de controle social e jurídico na região não impedem que o autor assuma uma posição cética a respeito das possibilidades de integração social dos indígenas. $\mathrm{O}$ relato da trajetória de um peão de origem autóctone assume tom de parábola: comprado por um fazendeiro que "lhe dedicava paternal affecto", através do trabalho chegara a possuir mais de duzentas cabeças de gado; ao reencontrar-se com os familiares nômades, no entanto, abandonou todas as suas posses e retornou "como pária" para as selvas. ${ }^{25}$ A condição de pária, no caso, é atribuída não à perseguição dos sertanejos, mas à "incoercivel força de atavismo ${ }^{26}$ da sua raça", o que significava imputar aos próprios indígenas sua condição de elemento à parte na sociedade sertaneja. Observe-se que, apesar de condenar a prática da venda de crianças indígenas, Hermano acaba por ver nela uma oportunidade de ascensão social, desde que esse instinto de retorno à condição primitiva não superasse o aprendizado adquirido no convívio com os demais.

Parte significativa das observações do viajante em seu intercâmbio com os indígenas, todos eles "semi-civilizados" (ou "semi-selvagens"), será

\footnotetext{
${ }^{23}$ Id., 1936, p. 235.

${ }^{24}$ Ibid., p. 236.

${ }^{25}$ Ibidem, p. 86.

${ }^{26}$ Ibidem, p. 86. O fenômeno do atavismo faz referência ao que seriam formas de degeneração biológica determinantes da manifestação de traços psíquicos e físicos do homem incivilizado no homem moderno, conduzindo a atitudes próprias às etapas primitivas do desenvolvimento humano. MURARI, Luciana. Brasil, ficção geográfica. Ciência e nacionalidade no país d'Os sertões. São Paulo: Annablume, 2007, p. 169.
} 
feita a partir do contato com os carajás abrigados no Posto Indígena Santa Isabel, localizado na Ilha do Bananal, com o ensejo de "penetrar no intimo convívio dos bugres e focalizar os quadros mais attrahentes da sua existencia rudimentar." ${ }^{27}$ Os registros amadorísticos do observador demonstram a impossibilidade do diálogo intercultural, seja pela assimilação precária da língua, ${ }^{28}$ pelo exame assistemático ou pela predisposição negativa:

Conforme me informaram, na tribu permitte-se a polygamia desde que o homem se submetta a tratar e sustentar as familias que constituir. Aqui descubro unicamente um grande amoroso que mantem duas mulheres, e, como a subsistencia de um indio é coisa facilima, não atino o motivo por que então perdura a sobriedade nupcial. Indago isso dos selvicolas, mas elles não adiantam nada, rindo gostosas gargalhadas. Será entretanto por causa da consideração saliente de que gosa o sexo frágil nesta nação, ao contrario do que acontece commumente entre os aborigenes? ${ }^{29}$

Observa-se, nesse ponto, um juízo da cultura indígena baseado no mito que associa a pressuposta abundância da natureza brasileira a uma sobrevivência fácil e despreocupada, o suficiente, naquele caso, para incentivar a poligamia.

Mais adiante, ao tratar ainda de sua estadia na ilha do Bananal, o narrador anota seu espanto em face da dedicação dos javaés à agricultura, recorrendo novamente à ideia da desnecessidade de trabalho. As grandes, diversificadas e bem cuidadas plantações seriam dispensáveis no cenário local, e pareciam tão mais espantosas à medida que o povo javaé é tido como mais atrasado que os carajás. Sua avaliação inicial dos primeiros baseia-se no estranhamento em face de atitudes interpretadas como "deseducação": ocupam as barracas dos brancos com suas esteiras, cospem no chão, mexem nos objetos alheios e tocam no rosto dos adventícios para sentir sua barba, em razão do estranhamento em relação aos pelos faciais dos brancos. ${ }^{30}$

Esses sinais de desconsideração em relação aos atributos da individualidade, do decoro e da propriedade, manifestados em seu primeiro encontro com os javaés, parecem suficientes para que o autor os considere dotados

\footnotetext{
${ }^{27}$ Ibidem, 1935, p. 135.

${ }^{28} \mathrm{Em}$ passagem adiante, o jornalista elabora um pequeno vocabulário da língua carajá, publicado, em suas palavras, "afim de que os futuros turistas do Araguaia contem com semelhante auxilio para relacionar-se com os seus indios". A lista, que não chega a preencher uma página, contém substantivos de uso comum, como nomes de alimentos, plantas e animais, da natureza, objetos cotidianos, alguns poucos adjetivos e nomes próprios. Ibidem, p. 147-148.

${ }^{29}$ Ibidem, p. 136.

${ }^{30}$ Ibidem, p. 275.
} 
de "um raciocinio apenas libertado da animalidade". ${ }^{31}$ Em contradição com essa lógica evolucionista subjacente, o sertanista diz negar-se a acreditar que os brancos tivessem chegado a se comportar, durante uma refeição, como aqueles nativos cujos "[d]edos sordidos entram, remexem e saem das caçarolas, os restos de qualquer pedaço mal servido voltam outra vez a boiar na sujidade do caldo, as boccas escancaradas cospem espinhas sem nenhum pudor" 32 . O termo "civilização" encontra aí o sentido da normatização da conduta que, como demonstrou Norbert Elias, apenas no século XVIII passou a guiar o comportamento das elites europeias. ${ }^{33}$ Hermano mostra-se ciente da historicidade desse processo, mas prefere considerar inadmissível que os antepassados da chamada "humanidade culta" tivessem algum dia adotado comportamento similar.

A observação da conduta indígena nesses relatos de viagem esbarra ainda no fato de que os nativos com os quais o viajante chega a entrar em contato estavam já imersos na cultura dos brancos e dos sertanejos. Daí resultavam comportamentos e estratégias de negociação que pareciam ao autor particularmente bizarros. Quando em questão está a obtenção de "objetos interessantes de usança do povo", em geral recolhidos pelos visitantes como presentes ou souvenirs, considera o narrador que "[e]sta especie de commercio tem um cunho paradoxal, revolucionario e depende exclusivamente das scismas dos bugres pelos objetos das suas particulares preferencias". Isso porque o valor exigido na troca de um objeto poderia parecer excessivo ou insignificante, conforme a estima que lhe dedicava seu possuidor. Isso parece estranho ao narrador, gerando longas negociações e resistências aguerridas se os indígenas "se cuidam de embirrar". ${ }^{34}$

Mais problemático é o registro da conspurcação do comportamento indígena em face do contato. Depois de afirmar seu desconhecimento da ideia de propriedade vigente na legislação brasileira, cita-se o suposto hábito dos autóctones de tudo subtrair dos cristãos, negando as acusações, adotando

\footnotetext{
${ }^{31}$ Ibidem, p. 275.

${ }^{32}$ Ibidem, p. 278.

${ }^{33}$ Segundo Norbert Elias, o processo de modernização dos costumes consistia em um conjunto de aprendizados no sentido do controle do corpo e das emoções, da adoção de atitudes brandas e da automatização dos rituais da polidez e da cortesia. Em um contexto de promoção da racionalidade e do desenvolvimento intelectual do indivíduo, a mente promovia a repressão dos instintos. O termo "civilidade" veicula, nesse contexto, um ideal de comportamento que pressuporia a superioridade intelectual e cultural do homem urbano e instruído, criando assim formas de segregação social. ELIAS, Norbert. O processo civilizador. volume 1. Uma história dos costumes. Tradução Raul Jungman. $2^{\mathrm{a}}$ ed. Rio de Janeiro: Zahar, 2011.

${ }^{34}$ SILVA, 1935, op. cit., p. 128.
} 
expressões faciais ingênuas e demonstrando absoluto desentendimento. As mesmas "espertezas", na definição do autor, seriam também praticadas contra seu próprio povo, sobretudo os "chefes de familia trabalhadores". Pior ainda, o contato teria conduzido a comportamentos condenáveis nos termos da própria cultura autóctone:

Ainda certos joven [sic] ladinos, que nas suas excursões mantiveram contacto intensivo com os sertanejos, desrespeitam a religiosidade da tribu, effectuando aproveitaveis sacrilegios nos tumulos dos recem-fallecidos. Daí usurpam os alimentos que os parentes dos mortos collocam, com o intuito de sustentar as almas queridas durante as jornadas para as mansões longinquas, E saciam-se do bom passadío, desde que os incautos parentes se convencem da extraordinaria fome dos pobres espiritos saudosos..$^{35}$

A sentença irônica, assentada em um aparente respeito pela religiosidade indígena, demonstra os danos da assimilação, embora o autor mostre-se pouco interessado, ao longo da narrativa, na manutenção da integridade de seu sistema de crenças. A condenação desse comportamento aponta para a ruptura das normas do mundo civilizado, porém agravada pelo disfarce espúrio de um pretenso desconhecimento do direito à propriedade e pelo comportamento explicitamente rético e cínico adotado por membros da tribo já situados nas fronteiras entre diferentes culturas.

Os xavantes, por outro lado, simbolizavam a possibilidade de conhecimento de nativos ainda em seu estado "original", o que os tornava objetos preciosos de estudo. A realização de contato com essa tribo será um dos principais objetivos da viagem mais ousada promovida por Hermano. A chamada "Bandeira Anhanguera", expedição composta por 40 homens, partiu de São Paulo em julho de 1937, em direção a Goiás, atendendo aos propósitos de promover a incorporação efetiva ao país de novos territórios, ainda não mapeados, e de "indios completamente divorciados da nossa civilização". ${ }^{36} \mathrm{Na}$ preleção em que apresentou seu projeto à elite paulistana em busca de suporte à iniciativa, em tom hiperbólico o escritor definiu essas tribos como "os mais numerosos representantes do homem primitivo sobre a terra, vegetando de forma absoluta na edade da pedra, estratificados os primeiros passos das criaturas racionaes." ${ }^{37}$ À "Bandeira moderna" foi conferido um caráter científico, de modo a difundir um discurso que afugentasse acusações de benefício

\footnotetext{
${ }^{35}$ Ibidem, p. 129.

${ }^{36}$ Sobre essa expedição, ver MURARI, Luciana. No rumo dos sertões inexplorados: a aventura da bandeira Anhanguera de São Paulo à Serra do Roncador (1937). Revista de História (São Paulo), n. 179, a04819, 2020. http://dx.doi.org/10.11606/issn.2316-9141.rh.2020.159762.
}

${ }^{37}$ SILVA, Hermano Ribeiro da. Os sertões do Brasil. O Estado de São Paulo, 26/3/1937, p. 3. 
pessoal e legitimasse o apoio das instituições científicas e culturais de São Paulo. Nesse sentido, um dos objetivos do grupo era "a viavel reunião de uma preciosa copia de investigações ethnographicas e a respectiva collecta e classificação do completo material aborigene de differentes agrupamentos." ${ }^{38}$

$\mathrm{Na}$ distribuição de tarefas entre os membros da expedição, coube a Hermano Ribeiro da Silva e Darcy Bandeira de Mello ${ }^{39}$ a produção de tais estudos, embora nenhum dos dois tivesse realizado estudos especializados. ${ }^{40} \mathrm{~A}$ história do contato da Bandeira com os xavantes foi narrada pelos três cronistas da expedição - Bandeira de Mello, Francisco Brasileiro e Antonio Senatore - e por algumas notícias enviadas à imprensa. A narrativa mais completa é a do líder da vanguarda do grupo, que descreveu sua estratégia de contato como um ataque-surpresa. Depois de identificar a trilha que conduzia à aldeia, rumaram em sua direção, chocando-se contra dois nativos, que gritaram para avisar os restantes. Inicia-se assim a dita ofensiva: "os homens nos flexavam, protegendo a retirada das mulheres e crianças. Cunhãs apressadas carregavam os filhos e as esteiras". Em atitude "pacífica", os forasteiros acenaram para os eles, indicando a oferta de objetos, o que reduziu aos poucos o lançamento de flechas e deu início a um curto instante de trégua:

Um deles se adiantou, segurando em uma das mãos o arco e na outra girando em molinete a pesada borduna. Fui então a seu encontro. Êle, porém, estacou em determinada distância, fincou o cacete no chão e me dirigiu a palavra com gestos largos e agressivos, batendo os pés, dando com as mãos como a nos mandar embora.

Mas foi um instante apenas. Nossos ouvidos não puderam reter o som de suas falas. Uma gritaria infernal e um ataque rápido e envolvente fez com que nos reuníssemos no centro da aldeia, e então, como um recurso inofensivo, soltamos poderosos foguetões que tombaram assustadoramente pelo socavão da serra...

O efeito foi imediato. Abandonaram o ataque e, aos trancos, aos trambolhões e aos pinchos, fugiram para o cerrado. Ficamos senhores da aldeia. ${ }^{41}$

\footnotetext{
${ }^{38}$ NO RUMO dos sertões inexplorados. O Estado de São Paulo, 13/5/1937, p. 11.

${ }^{39}$ Filho do capitão Manuel Silvino Bandeira de Mello, Darcy havia viajado em 1930 com o objetivo de atravessar a ilha do Bananal por terra, de Santa Isabel até o Rio Javaés, para organizar o Posto Felicidade Indígena. A tentativa não foi bem sucedida. Seu ingresso na Bandeira Anhanguera, quando já havia há muito retornado do sertão, deu-se por convite de Hermano, mas sua passagem pela Bandeira foi repleta de tensões. MELLO, Darcy Bandeira de. Entre índios e revoluções. (Pelos sertões de São Paulo, Mato Grosso e Goiás de 1911 a 1941). São Paulo: Soma, 1980. RODRIGUES, Patrícia de Mendonça. Relatório de identificação e delimitação: Terra Indígena Utaria Wyhyna (Karajá) / Iròdu Iràna (Javaé). Brasília: FUNAI/PPTAL, 2008.

${ }^{40} \mathrm{O}$ interesse de Hermano Ribeiro da Silva pelos estudos indígenas manifestara-se, em Garimpos de Mato Grosso, por meio de um projeto de escrever um livro sobre os crenaques. SILVA, 1936, op. cit., p. 211.

${ }^{41}$ BRASILEIRO, Francisco. Na Serra do Roncador. (A vanguarda da Bandeira Anhanguera). Companhia Editora Nacional, 1938. p. 190-191.
} 
O episódio da invasão da aldeia xavante é narrado com real espírito de conquista, e assume uma inflexão bélica ao associar a incursão a um ataque dos indígenas, e não a sua defesa, valorizando o caráter temerário da aventura e, portanto, o heroísmo do grupo. ${ }^{42}$

Uma vez na aldeia, as casas foram percorridas para a coleta de material, "depositando, em troca, espelhos, pentes, facas e canivetes 'Corneta'." Enquanto isso, a aldeia era fotografada e "observados dedutivamente os usos e costumes, como a oportunidade nos oferecia." ${ }^{33}$ De retorno, "extenuados, famintos, mas contentes", os expedicionários foram surpreendidos por flechadas, tidas como pagamento "pela visita que lhes fizemos pela manhã." ${ }^{44} \mathrm{O}$ episódio mais épico da jornada é encerrado de forma abrupta e sem maiores detalhes sobre as supostas descobertas do grupo, retomando o habitual relato das agruras vividas durante a marcha.

A definição mais generosa do significado do evento para a nação brasileira foi veiculada pelo padre Nunes, da Missão de Catequese dos Índios Xavantes, incorporado à Bandeira em face de seu objetivo comum de fazer contato com a tribo, de modo a criar condições para sua "pacificação". Para ele, espírito patriótico e o empenho missionário teriam sido perfeitamente recompensados pelo sucesso da iniciativa:

Já não são pequenos os trabalhos culturaes da Bandeira neste valle do rio das Mortes. Do topé da Serra ainda avistamos as matas marginaes do curso. É possivel que a grande bacia do Kuluene, no planalto, offereça campo ainda mais vasto para as observações scientificas da expedição. Essa terra sabemos que é irrigada por numerosos affluentes desse rio, e acreditamos mesmo que seja morada de outras tantas tribus selvagens [...]

\footnotetext{
${ }^{42} \mathrm{Em} 1938$, outra expedição com os mesmos objetivos chega à região, a "Bandeira Piratininga", liderada por Willi Aureli, que compunha com Hermano o grupo que Carlos Alberto Mendoza denomina "sertanistas de bandeira". MENDOZA, Carlos Alberto Casas. Nos olhos do outro: nacionalismo, agências indigenistas, educação e desenvolvimento, Brasil-México (1940-1970). Tese (doutorado) em Ciências sociais. Campinas: Unicamp, 2005. p. 59. Essa iniciativa utilizou-se dos mesmos expedientes do grupo de Hermano para invadir uma aldeia xavante. A crítica a eles foi intensa e rendeu uma longa polêmica sobre a abordagem dos indígenas, sobre a responsabilidade e a necessidade de controle do estado sobre tais iniciativas. A antropóloga Heloísa Alberto Torres, membro do Conselho de Fiscalização de Comissões Científicas, chamou a atenção para a inutilidade e mesmo para os prejuízos causados à causa da pacificação por esses contatos. A SNRA. HELOISA Alberto Torres inpugnou [sic] a licença do Conselho de Fiscalização de Comissões Cientificas á "Bandeira Piratininga". A Gazeta, Florianópolis, 21/9/1938, p. 2. O Conselho havia sido criado pelo decreto n. 22.698, de 11 de maio de 1933, que obrigava as caravanas de penetração, tanto nacionais como estrangeiras, a submeter-se a sua fiscalização. $O$ decreto foi citado e comentado por Hermano. SILVA, 1935, op. cit., p. 25. Sobre a atuação do Conselho, ver GRUPIONI, Luís Donisete Benzi. Coleções e expedições vigiadas: os etnólogos no Conselho de Fiscalização das Expedições Artísticas e Científicas no Brasil. São Paulo: Hucitec/Anpocs, 1998.

${ }^{43}$ BRASILEIRO, op. cit., p. 191.

${ }^{44}$ Ibidem, p. 191.
} 
De maior importancia ainda foi o contacto pacifico que a Bandeira soube manter com os moradores de uma das grandes aldeias centraes dos Chavantes; não reputo longinqua a pacificação desses indios destituidos, por assim dizer, de espirito guerreiro, como tivemos occasião de verificar. ${ }^{45}$

É curioso que, ao final, a belicosidade dos temidos xavantes pareça enfraquecida, o que talvez possa ser explicado pelo desejo do sacerdote de fazer com que a catequização parecesse mais fácil do que se supunha até o momento.

Nos dizeres do religioso, o material etnográfico que havia sido coletado permitia a única conclusão de que "a tribu vive em plena edade da pedra", descoberta incapaz de justificar a declaração de que a Bandeira havia sido "o maior feito de São Paulo bandeirante". Ele investe, sobretudo, na ideia de que aquela região escondia um potencial ainda maior de assimilação, considerando o planalto em volta do rio Kuluene o "centro provavel de irradiação de varias raças americanas", e, portanto, um território merecedor de exploração sistemática. ${ }^{46}$ Considerando próximo o contato com os xavantes, o religioso parece planejar futuras incursões. Em perfeita sintonia com suas declarações, o próprio Hermano Ribeiro da Silva difundiu, via rádio, uma particular interpretação dos eventos do "contato", em uma mensagem que buscava legitimar a estratégia de aproximação em função do que seriam seus benefícios para a cristianização dos indígenas:

Estava ao nosso fácil alcance conseguir informações mais completas da tribo Chavante. Bastaria aprisionar alguns índios, servindo-nos da oportunidade de nos encontrarmos bem armados na ocasião. Porém, qualquer gesto nosso demonstrando fins guerreiros, prejudicaria ação futuros [sic] pacificadores, ao mesmo tempo, chocando-se com o espírito de paz e amizade que norteia nossa Bandeira o seu plano de contacto essa [sic] valorosa tribo. ${ }^{47}$

As demais memórias disponíveis acrescentam mais informações à reconstituição do evento. Na versão de Bandeira de Mello, ressalta-se o registro de que "todas aquelas espetaculares e inéditas cenas eram fotografadas e filmadas", em consonância com o caráter midiático assumido pela Bandeira Anhanguera. ${ }^{48}$ Esse memorialista elenca com maiores detalhes elementos da cultura material dos indígenas, considerando a existência de panelas de

\footnotetext{
${ }^{45}$ BANDEIRA Anhanguera. Mensagens enviadas do acampamento da "Bandeira" na Serra Divisora. O Estado de São Paulo, 4 nov. 1937, p. 2.

${ }^{46}$ Idem.

${ }^{47}$ Hermano Ribeiro da Silva, apud. MELLO, op. cit., p. 231-232.

${ }^{48} \mathrm{~A}$ Bandeira Anhanguera foi patrocinada, logo no início de sua organização, pelo jornal O Estado de São Paulo e pela Rádio Bandeirante. A contrapartida do grupo era o envio regular de mensagens para a divulgação de notícias cotidianas da aventura. NO RUMO dos sertões inexplorados. O Estado de São Paulo, 12/5/1937, p. 11
} 
alumínio nas malocas como resultado dos "ataques mortíferos que faziam a civilizados e carajás", ${ }^{49}$ ao mesmo tempo em que busca desfazer expectativas, considerando a aparência física do xavante como "nada de especial." 50

No registro do diário do fotógrafo Antonio Senatore, o sucesso da empreitada seria devido ao fato de que havia poucos homens na aldeia no momento de sua invasão, cerca de 40 , pois a maioria deles encontrava-se em expedições de caça ou coleta. Segundo ele, os expedicionários voltaram “todos alegres e satisfeitos pelo resultado feliz, que jamais imaginaríamos resolver com tanta facilidade." Esperavam que fosse evidente para os nativos que a incursão deles, ainda que realizada de modo furtivo, havia respeitado seus animais e objetos de valor, "excetuando alguns artigos indispensáveis para o museu de São Paulo, que trocamos por várias quinquilharias (...)." ${ }^{51}$ Além dos "poderosos foguetões" utilizados para o ingresso na aldeia, os expedicionários haviam lançado um rojão e disparado três tiros de mosquetão durante sua retirada. ${ }^{52}$

O episódio da invasão do território xavante foi louvado pelos representantes da Bandeira como seu feito mais heroico, uma vez que a subida à serra do Roncador acabou não se concretizando. No balanço realizado por Francisco Brasileiro, eles haviam sido os primeiros brancos a ingressar em uma aldeia daquela etnia, além de terem sido responsáveis por identificá-los como xerentes - o que era uma alegação equivocada, já que essa origem tinha sido defendida anteriormente pelo líder da expedição, como vimos. ${ }^{53} \mathrm{~A}$ imprensa, igualmente, celebrará, ao menos em um primeiro momento, o sucesso da missão, saudando o evento como o maior êxito da expedição. ${ }^{54}$

\footnotetext{
${ }^{49}$ MELLO, op. cit., p. 228.

${ }^{50}$ Ibidem, p. 230.

${ }^{51} \mathrm{O}$ material coletado pela Bandeira Anhanguera foi entregue ao Museu Paulista e posteriormente transferido, no total de oito peças, para o Museu de Arqueologia e Etnologia da USP, onde se encontra atualmente.

${ }^{52}$ SENATORE, Antonio. Viagem à serra do Roncador. 1937. São Paulo: Lemos, 2001. p. 64-65.

${ }^{53}$ BRASILEIRO, op. cit., p. 202.

${ }^{54}$ Mais tarde, membros do Serviço de Proteção ao Índio (SPI) vão condenar abertamente, conforme reportou Bandeira de Mello em suas memórias, o uso dos "inofensivos fogos adrianinos soltos para o ar, com o objetivo de afugentar os selvagens". Em sua defesa, o explorador argumentou que o ardil havia poupado vidas, lembrando que uma expedição oficial de pacificação enviada em 1941 havia sido exterminada por eles, e que os primeiros contatos bem-sucedidos do SPI só serão realizados em 1944. MELLO, op. cit., p. 232. Na verdade, o controle efetivo sobre um grupo xavante foi obtido em 1946, pelo SPI, depois de já implantado o núcleo de Xavantina pelos membros da expedição Roncador-Xingu, à margem direita do rio das Mortes. A aldeia de São Marcos foi construída pelos xavantes sob a supervisão dos sacerdotes salesianos, entre 1956 e 1957. MONTERO, Paula. Selvagens, civilizados, autênticos. A produção das diferenças nas etnografias salesianas (1920-1970). São Paulo: Edusp, 2012. p. 102-103.
} 
“Os nossos bugres”: As expedições de Hermano Ribeiro da Silva ao Brasil central e a ...

\section{3. "Tornar os selvicolas elementos uteis de trabalho para a nossa civilização": política estatal e ação missionária para os povos indígenas}

Hermano Ribeiro da Silva buscou não apenas descrever e diagnosticar a realidade do Brasil central como também especular sobre as melhores políticas a serem adotadas para sua integração efetiva ao país. No caso da questão indígena, ele havia definido o estado civilizacional dos nativos que encontrou com o objetivo de avaliar suas perspectivas de incorporação à sociedade brasileira e atuar efetivamente em prol de sua pacificação. É nesse sentido que, em face das entidades que já atuavam junto aos indígenas, o escritor expôs suas observações e emitiu seus próprios juízos acerca do enfrentamento da questão.

As experiências vividas e as formulações sobre os selvícolas elaboradas pelo sertanista desenrolam-se no contexto de uma política indigenista inaugurada em 1910 com a criação do Serviço de Proteção aos Índios e Localização de Trabalhadores Nacionais (SPILTN). Com a Revolução de 1930 e o processo de reorganização da burocracia estatal, a política brasileira para os nativos passa por consideráveis mudanças. Em 1930, a 26 de novembro, o governo provisório cria, através do decreto n. 19.433, o Ministério dos Negócios do Trabalho, Indústria e Comércio. Diferentes repartições públicas foram agrupadas pelo novo ministério, dentre elas o Serviço de Proteção aos Índios (SPI) ${ }^{55}$. Ao final do governo provisório, em 12 de julho de 1934, pelo decreto n. 24.700, o SPI é transferido para o Ministério da Guerra. O discurso passa a centrar-se na integração do nativo à sociedade, conforme a política indigenista anterior, mas com ênfase na "nacionalização do indígena", ou seja, na submissão da política indigenista aos desígnios da geopolítica brasileira. ${ }^{56}$

A partir desse novo contexto, passa a ser defendido o argumento de que os povos autóctones poderiam contribuir, com suas qualidades físicas e sua adaptação ao clima, para a proteção das fronteiras nacionais, tornando-se, assim, agentes dos planos governamentais. O SPI passa a compor a Inspetoria Especial de Fronteiras, ficando ao encargo do Ministério da Guerra analisar a legislação indigenista afim de adaptá-la aos interesses de defesa das fronteiras. No ano de 1936, com o decreto n. 736, de 6 de abril, foi aprovado em caráter

\footnotetext{
${ }^{55}$ Com a transferência do "Serviço de Localização de Trabalhadores Nacionais" para o Serviço de Povoamento do Solo, vinculado ao Ministério da Agricultura, Indústria e Comércio, em 1918, o SPILTN já havia se tornado SPI (Serviço de Proteção aos Índios). RAMOS, Jair de Souza. O poder de domar do fraco: construção de autoridade pública e técnicas de poder tutelar nas políticas de imigração e colonização do Serviço de Povoamento do Solo Nacional. Horizontes Antropológicos, v. 9, n. 19, p. 15-47, 2003.

${ }^{56}$ GAGLIARDI, José Mauro. O indígena e a República. São Paulo: Hucitec, 1989. ROCHA, Leandro Mendes. A política indigenista no Brasil. 1930-1967. 2. ed. Goiânia: Editora UFG, 2003.
} 
provisório o Regulamento do Serviço de Proteção aos Índios, que mantinha os propósitos de proteção e assistência e estabelecia o objetivo de "pôr em execução medidas e ensinamentos para a nacionalização dos selvicolas, com o objectivo de sua incorporação á sociedade brasileira." ${ }^{57}$

Nessa conjuntura, o termo "nacionalização" estava ligado à ideia de incorporação dos autóctones à sociedade, "encimando as tarefas de proteção e assistência, movendo-se sobre o solo de representações pretéritas acerca do índio e suas potencialidades, isto é, a de guarda de fronteiras." ${ }^{58} \mathrm{O}$ tratamento dos nativos situados em áreas limítrofes passa a ser privilegiado, em detrimento daqueles que habitavam o interior. Para atender a isso, os postos indígenas foram classificados em: postos de atração, vigilância e pacificação; postos de assistência, nacionalização e educação. Para Gagliardii" " "nos postos, o indígena deveria ser educado para o cumprimento dos deveres cívicos (...)."

Como vimos, o contato inicial de Hermano com o trabalho do SPI deu-se em 1932, na ilha do Bananal. O Posto Indígena Carajás, criado em 1927, foi regido pelo Capitão Manuel Silvino Bandeira de Mello, ajudante próximo de Rondon. Já em 1928, passara a se chamar Posto de Redenção Indígena. Localizado em Santa Isabel, foi instalado como marco oficial da pacificação daquela tribo. No entanto, extinto em 1930 em função dos realinhamentos políticos relacionados à Revolução e à consequente reestruturação da política indigenista, ficou abandonado até 1939. Seu estabelecimento, narrado por Hermano a partir de depoimentos colhidos no local, iniciou-se com a construção de oito casas de barro, caiadas e cobertas com palha. A essa sede inicial foram agregadas benfeitorias, dando início a trabalhos de produção agrícola. O balanço do escritor é bastante simpático às realizações do Posto, do ponto de vista da promoção de um cenário "civilizado", liderado por uma figura capaz de arregimentar a colaboração voluntária dos indígenas com sua "missão exhaustiva":

Assim, ao cabo do primeiro anno, se instituia e se mostrava aos olhos dos viajantes solitarios um centro de vida e de progresso nas abandonadas distancias do Araguaia. Arregimentados os indios, além das 200 almas da aldeia local do capitão Malohá, outros, em bandos numerosos, vinham de longe a frequentar o bulicio da praça atrahente. Nos moldes da catechese leiga - segundo o testemunho geral que encontrei - não se poderia desejar

\footnotetext{
${ }^{57}$ COLEÇÃo das Leis da República dos Estados Unidos do Brasil. Rio de Janeiro, Imprensa nacional, v. I, janeiro a maio, 1936, p. 348.

${ }^{58}$ LIMA, Antonio Carlos de Souza. Um grande cerco de paz: poder tutelar, indianidade e formação do Estado no Brasil. Petrópolis: Vozes, 1995. p. 280.
}

${ }^{59}$ GAGLIARDI, op. cit., p. 277. 
um trabalho mais digno. É que, devotado inteiramente á causa, se achava á testa da emprêsa Manuel Silvino Bandeira de Mello, antigo pacificador dos caingans do noroeste de São Paulo, e cujo nome é proclamado aqui com os melhores elogios, principalmente por parte dos selvagens, que lhe guardam extraordinaria amizade. ${ }^{60}$

Apesar desses elogios à implantação do Posto, o escritor mostra-se cético quanto ao cumprimento eficiente da missão civilizadora pelas instituições estatais. Segundo ele, os funcionários do SPI, "exilados da sociedade", submetiam-se a Inspetorias sediadas e em cidades, "departamentos quasi innocuos e perdularios dos dinheiros publicos”. A má reputação do dirigente dessas repartições, "homem muito aquem da altura das suas obrigações," indicava o desperdício de verba e a inação dos funcionários que dirigiam a entidade no Rio de Janeiro em face da má administração regional, o que sinalizava "as mysteriosas garras de um deploravel proteccionismo politico." ${ }^{61}$

O estado de degradação das estruturas do Posto do SPI depois de dois anos de abandono oferece a ele outro argumento. Os próprios indígenas, carentes de um "mando energetico", "vão a pouco e pouco arrazando tudo, como as crianças fazem com os seus brinquedos", de acordo com a analogia tantas vezes utilizada pelo viajante para se referir à índole dos nativos. Para agravar a situação, ele apresenta o funcionário Benedito, "o unico christão que permanece ainda no Posto sem perceber qualquer pagamento (...)", como alguém completamente desprovido de capacidades intelectuais mínimas. A avaliação da extinção do Posto pelos agentes da política indigenista oficial permite acompanhar a continuidade da situação testemunhada pelo sertanista, conforme o Relatório de atividades do Ministério da Guerra referente ao SPI, publicado em 1934:

(...) o abandono dos postos de attracção pelos indios pacificados, que retornaram á matta e recomeçaram as hostilidades (...) o abandono das lavouras e campos de criação, a perda de machinas, installações e utensilios custosos: roubos e dispersão de gado, enfim para acabar de aniquilar o que restava do Serviço, surgio verdadeiro assalto aos bens da Ação e dos indios, accumulados nos postos, como aconteceu no Posto da "Ilha do Bananal", em Goyas. ${ }^{62}$

Esses problemas político-administrativos somam-se, na avaliação de Hermano, à dificuldade de encontrar "pessoas alentadas de profundo ideal superior", dispostas a exercer cargos que exigiam "inimaginaveis sacrificios".

\footnotetext{
${ }^{60}$ SILVA, 1935, op. cit., p. 123.

${ }^{61}$ Ibidem, p. 123-124.

${ }^{62}$ Apud. ROCHA, op. cit., p.52-53.
} 
Para o autor, mesmo que leigos se mostrassem dispostos a exercer tal "obra humanitaria" 63 , o ensino cívico não era suficiente para incorporar os indígenas à sociedade. Caso o governo federal voltasse a empreender o Serviço de Proteção, deveria conferir a ele uma orientação católica, com participação ativa de sacerdotes, pois "[n] egar, ou pretender destruir os serviços prestados pelos servos da igreja, praticamente demonstrados nas dezenas de colonias que mantêm nas solidões do Brasil, será por certo ingratissimo." ${ }^{64}$

As incursões dos missionários religiosos - particularmente, irmãos dominicanos, capuchinhos e salesianos, além de pastores protestantes - foram consideradas pelo expedicionário paulista como experiências de iluminação em um mundo de atraso e obscurantismo. Em geral, os missionários eram elogiados pelos seus grandes feitos de bravura e por sua persistência na promoção da catequização, além de se mostrarem responsáveis pela aquisição de conhecimentos acurados sobre o território do Brasil central e seus indígenas. A partir de informações obtidas junto a esses agentes e suas obras, Hermano se informa sobre aspectos da cultura indígena e da geografia local. ${ }^{65}$

Em vilas e povoados do vale do Araguaia, o viajante observa os resultados da ação de implantação das "bases da civilização christã" religiosas. Ele considera prejudicial a imposição aos autóctones do modo de vida rotineiro de uma sociedade sedentária, o que resultaria em rebeldia, fuga, animosidade e propagação de doenças até então desconhecidas. Os métodos utilizados no trabalho dos sacerdotes são tidos como os únicos adequados, pois baseados em "infindaveis subtilezas do espirito afim de que frutifique a conquista pacifica" ${ }^{67}$. Essas "sutilezas" consistiam: na aprendizagem da língua indígena, tida como ferramenta essencial ao processo de cristianização; em um tratamento bondoso somado a uma paciência inabalável; em "aconselhal-os como as crianças"; 68 na lenta impressão em suas mentes da ideia de Deus, retirando deles suas superstições, fetiches e feitiçarias; em visitas constantes às aldeias, "participando de seus repugnantes alimentos"; no empréstimo de ferramentas e objetos prediletos, para que não se habituassem "a viver no

\footnotetext{
${ }^{63}$ SILVA, 1935, op. cit., p. 123-124.

${ }^{64}$ Ibidem, p. 121.

${ }^{65}$ Como exemplos, citamos as inscrições rupestres atribuídas a uma etnia desconhecida pelo Frei Luiz Palha, dominicano da catequese de Conceição, e o livro do sacerdote salesiano Nicolau Badariotti, Exploração do norte de Mato Grosso, região do Alto Paraguay e Planalto dos Parecis, publicado em 1898. SILVA, 1936, op. cit., p. $49,212$.

${ }^{66}$ SILVA, 1935, op. cit., p. 187.

${ }^{67}$ Ibidem, p. 196.

${ }^{68}$ Ibidem, p. 196.
} 
ocio da caridade mal compreendia [sic]"; ${ }^{69}$ no direcionamento dos jovens às aulas fornecidas por eles, inclusive para a educação das moças indígenas. $\mathrm{O}$ uso desses métodos visava, para o narrador, "proteger os infelizes aborigenes."70

Como se vê, trata-se de uma ação paternalista e colonialista voltada para incutir neles um novo modo de vida, com base em uma recusa completa de sua cultura própria. 0 entusiasmo com que o narrador louva a persistência dos missionários combina-se, na narrativa, com a observação de que a ação educativa desses religiosos enfrentava contrariedades cotidianas, como a recusa dos alunos a usar roupas, a fuga para suas aldeias, os "motivos puerís" 71 arrolados pelos pais para retirá-los da escola. Mais uma vez, as possibilidades de "redenção" indígena parecem a Hermano limitadas. A exceção é a história de uma recém-nascida resgatada por um padre do ritual indígena que demandava seu sacrifício, em função da morte de sua mãe no parto. Entregue com relutância, pelo preço de um facão, ela foi criada pelos religiosos e se tornara a freira Sebastiana, "legitima india cherente", ${ }^{72}$ a única brasileira entre as freiras dominicanas francesas que atuavam no colégio para moças na missão. "Hoje é a professora bem-quista pela petizada da escola, querida pelos selvicolas excursionistas." ${ }^{73}$ Para o autor, trata-se de uma história de salvação espiritual, na versão mais otimista dos resultados da ação missionária.

Um dos religiosos com que Ribeiro da Silva travou mais intenso contato, desde suas primeiras expedições mineradoras no início da década de 1930, foi o salesiano João Fuchs, que comunicara a ele "uma multiplicidade de factos interessantissimos acérca dos boróros, a cuja pacificação os salesianos se dedicam estoicamente desde três dezenas de annos, aldeando-os progressivamente nas colonias agricolas installadas ao norte do Rio das Garças." 74 O padre, que vivia desde o início do século XX em Mato Grosso, surge nos relatos do sertanista publicados em 1936 como o pregador que levava a palavra divina para os garimpeiros, em sua grande maioria displicentes quanto às obrigações

\footnotetext{
${ }^{69}$ Ibidem, p. 196.

${ }^{70}$ Ibidem, p. 196.

${ }^{71}$ Ibidem, p. 197.

${ }^{72}$ Ibidem, p. 202.

${ }^{73}$ Ibidem, p. 203.

${ }^{74}$ Ribeiro da Silva registra o conhecimento prévio de trabalhos sobre os povos indígenas de autoria dos missionários salesianos, com destaque para A tribo dos boróros, publicado em português em 1919 e escrito pelo padre António Cobalchini, "que conseguiu estampar nas respectivas paginas, pela sciencia fundamentada na pratica da extensa vida decorrida em meio do gentío, as mais completas e as mais perfeitas investigações existentes na bibliografia aborigene, no concernente a uma determinada tribu.". SILVA, 1936, op. cit., p. 216. Sobre o trabalho dos missionários, ver MONTERO, op. cit.
} 
religiosas. $\mathrm{Na}$ viagem ao vale do Araguaia, Hermano reencontra o personagem atuando efetivamente junto aos bororós, para cuja exitosa pacificação ele teria contribuído decisivamente. A descrição do culto religioso é exemplar a respeito da forma como o relato define os resultados positivos do esforço missionário na região:

A devoção do povo edificou recentemente uma capella coberta e emparedada
com folhas de coqueiros. Ainda não houve tempo para construir bancos,
mas isso não impede que os fieis aí se reunam nas missas da manhã e nas
rezas da tarde. Sentam-se pelo chão de terra batida á maneira de bhudas e
ouvem attentamente as prégações do sacerdote, que são simplorias e repletas
de symbolos da vida diaria delles, conforme faz mister aos seus estreitos
entendimentos. Os companheiros são obrigados a integrar o côro dos canticos
religiosos, de que por felicidade se lembram um pouco pelas recordações da
educação da infancia. Cassio e Oscar possuem vozes aturaveis, Chico tem
boa vontade para ser barytono. Eu espreito a lucta que se trava entre elles, o
occultista Manoel Barreira e uma centenaria rheumatica. Os dois ultimos dão
sempre mostras de completo ciume, mexem-se e pigarreiam, porque desejam
puxar as ladainhas e não admittem concorrentes, no caso os meus amigos,
deploravelmente inconscientes das regras das cerimonias.

A avaliação dos métodos de catequização e de seus resultados mostra-se, na melhor das hipóteses, condescendente, somando-se à ironia na abordagem da apropriação sertaneja dos ritos religiosos. Seu tratamento humorístico da cena exemplifica o estilo literário do autor na comunicação de suas experiências, como um homem culto em contato com uma comunidade iletrada, e como observador mais arguto que seus companheiros ao reconhecer as limitações do contexto. É este o colorido mais característico de suas narrativas, ainda que o humor conviva com o julgamento etnocêntrico e faça parte dele.

Desde sua viagem anterior a Mato Grosso, o cronista observara a coexistência entre pregadores católicos e protestantes - adventistas e presbiterianos - nas vilas, observando que ambos recebiam a mesma audiência. Essa incluía os excursionistas, mesmo os pouco afeitos à vida religiosa em seu contexto de origem, como o próprio Hermano. Em Goiás, na expedição de 1932, ele encontra no Posto Adventista "um oásis de progresso ficado no abandono das solidões." 76 Em geral, não se sente tão solitário no sertão graças aos letrados religiosos. Embora a missão adventista aparentemente tenha surtido bons resultados, as limitações da cristianização são abertamente expostas. Uma delas era a dificuldade de aceitação das restrições alimentares da religião,

\footnotetext{
${ }^{75}$ SILVA, 1935, op. cit., p. 65.

${ }^{76}$ Ibidem, p. 77.
} 
o que exigia dos missionários que fizessem "muitas concessões ao rebanho impenitente e anarquizado."77

O principal problema parece ser, entretanto, o fato de que os indígenas não renunciavam ao nomadismo. Nesse caso, as escolas religiosas funcionavam de outubro a junho, período chuvoso, "submettendo-se elles então ao sedentarismo mais por força das chuvas e do flagello dos mosquitos que por amor á nossa civilização, coisa que não lhes importa, aliás, com algumas carradas de razão." ${ }^{78} \mathrm{O}$ chiste aparentemente crítico à modernidade não implica em relativizar seu juízo sobre as culturas nativas, tampouco o desvia de seus objetivos. Pelo contrário, a catequização é vista como uma etapa necessária ao propósito político categórico de promover o adensamento da ocupação do Brasil central. A existência de "selvagens" surge como um sintoma do povoamento precário, pois muitas tribos nativas ainda estariam dispersas pelo imenso território, sem que tenham sido transformadas pelos instrumentos da "civilização": o conhecimento e o domínio. ${ }^{79}$ Os ataques dos indígenas seriam também causas dessa escassez.

Para o sertanista, a catequese pela fé ainda constituía a melhor ferramenta para domesticar os selvagens, sendo as missões religiosas tidas como verdadeiras epopeias em paragens esquecidas pelo mundo. Dentre essas, afirma que "a catechese catholica supera todas as demais. Os indios, com as theogonias, as superstições (tabús e toténs), os animismos transfigurados, plasmam-se por excellencia para receber a orientação christã." ${ }^{80}$ Essa fala, que pressupõe um potencial de diálogo do misticismo católico com as crenças indígenas, é significativa, pois a política indianista no Brasil havia sido, até então, condicionada pelo "surto do positivismo ortodoxo" a instauração do regime republicano, que teria submetido as missões católicas “aos maiores ataques de febre anti-religiosa." 82 É possível que essa preferência pelo catolicismo, apesar da admiração pelos missionários protestantes, esteja também relacionada a sua coerência com a tradição cultural brasileira,

\footnotetext{
${ }^{77}$ Ibidem, p. 78.

${ }^{78}$ Ibidem, p. 223

${ }^{79}$ Ibidem, p. 223.

${ }^{80}$ Ibidem, p. 120.

${ }^{81}$ Positivistas ortodoxos eram aqueles que adotavam a obra de Auguste Comte na sua íntegra, tanto filosófica quanto religiosa, dentre os quais muitos eram filiados à Igreja Positivista do Brasil.

${ }^{82}$ Ibidem, p. 120.
} 
elemento não desprezível em face do orgulho heráldico do escritor, herdeiro presumido do bandeirantismo. ${ }^{83}$

Nesse sentido, compreende-se a importância antes de tudo simbólica da pacificação dos xavantes. Alguns missionários se extremaram na tentativa de alcançá-los, o que deu origem a eventos dramáticos na história do contato com essa tribo. Tendo travado relações com o padre suíço João Fuchs em sua viagem anterior, Hermano cruza novamente seu caminho em seu percurso no Araguaia em direção ao rio das Mortes, realizado em 1932 a bordo do barco Apache. ${ }^{84}$ Juntamente com o sacerdote Pedro Sacilotti, ${ }^{85}$ Fuchs mandara construir um rancho de pau-a-pique coberto com palha que deveria ser a base de uma colônia para os xavantes. Reportando-se a eventos posteriores, datados do verão de 1934, a narrativa registra ataques que conduziram à morte desses missionários, assim como a dos membros de uma expedição exploratória:

[0]s indios esmigalharam as cabeças dos sacerdotes a cacete, abandonando após os corpos. Refere a triste nova, além desse successo, o desapparecimento na região de um grupo de estrangeiros, que participavam do desbravamento da gleba atormentada. Estes, luctadores e audaciosos; aquelles, espiritos illuminados pelo estoicismo da fé inquebrantável - todos merecem, sem duvida o preito de reverente homenagem dos civilizados. Comquanto acalentassem ideaes diversos, reunem-se na phalange dos grandes sacrificados pela barbaria dos sertões. O padre Fuchs, velho de mais de 60 annos, sonhava pacificar os ferozes chavantes, a cujo escopo vinha dedicando ultimamente fervoroso e nobre empenho. De armas, carregava exclusivamente uma desvaliosa espingarda de chumbo, que lhe valia para abater pequenas caças imprescindiveis

\footnotetext{
${ }^{83}$ Essa imagem positiva do bandeirante, criada por certa literatura produzida principalmente entre as últimas décadas do século XIX e o início dos anos 1940, converteu-os em heróis nacionais e arquitetos dos atuais limites geográficos da nação, gerando uma tradição que foi empregada pelas elites paulistas para engrandecer suas origens. OLIVEIRA, João Pacheco de. O nascimento do Brasil e outros ensaios: "pacificação", regime tutelar e formação de alteridades. Rio de Janeiro: Contra Capa, 2016. SOUZA, Ricardo Luis de. A mitologia bandeirante: construção e sentidos. História Social. Campinas, n. 13, p. 151-171, 2007. No entanto, "bandeirante" não é uma categoria fixa, em meio a várias práticas e discursos. Para além de uma figura histórica do período colonial brasileiro, trata-se de uma invenção que é utilizada em diferentes contextos. WALDMAN, Thais Chang. 2018. Entre batismos e degolas: a presença bandeirante em São Paulo. Tese (Doutorado em Antropologia Social). Faculdade de Filosofia, Letras e Ciências Humanas, Universidade de São Paulo, São Paulo. No caso do período colonial, devemos manter em mente que, por trás das façanhas dos desbravadores, encobre-se a história dos milhares de índígenas, os "negros da terra", subjugados pelos sertanistas de São Paulo. MONTEIRO, John Manuel. Negros da terra: índios e bandeirantes nas origens de São Paulo. 3. ed. São Paulo: Companhia das Letras, 2000.

${ }^{84} \mathrm{O}$ nome, atribuído "em homenagem á aguerrida tribu dos pelle-vermelha do país do norte", relaciona-se ao fato de que o parceiro de Hermano nessa empreitada era o aviador norte-americano Howard Rinehart. Sua escolha também está relacionada à romantização da figura do indígena, o outro lado da acusação de seu barbarismo. SILVA, 1935, op. cit., p. 210-211.
}

${ }^{85} \mathrm{O}$ autor grafa, incorretamente, "Saielotti". 
á alimentação. O seu assassinio estatue com nitidez o índice dos incontaveis perigos e padecimentos reservados aos missionarios das nossas selvas. ${ }^{86}$

Antes de ser um desincentivo, para os aventureiros e exploradores do vale do Araguaia a agressividade dos xavantes os havia convertido em objeto de conquista, fazendo do desafio do contato um veículo para a celebridade, como feito inédito e como ato de bravura, em face do histórico das tentativas e das próprias mistificações a seu respeito.

Pouco depois da invasão da aldeia xavante pela Bandeira Anhanguera, foi registrada uma primeira aproximação de religiosos salesianos com a tribo, também ela malograda, tal como registrado por um balanço final da expedição publicado no jornal o Estado de São Paulo, a partir de notícias enviadas desde o Araguaia por Hermano:

Referiam ellas que na parte final de sua descida pelo rio das Mortes o padre Chevelon $^{87}$ e sua comitiva avistaram numa praia dois grupos distinctos de chavantes, um de homens, outro de rapazes. Conforme ao que declarára aquelle sacerdote, houve troca de presentes, á distancia, entre elles e os selvagens. 0 contacto assim se mantivera por dois dias e findos estes fôra elle alvejado, com seus companheiros, por numerosas flexas, uma das quaes o ferira levemente num dos braços. ${ }^{88}$

Em sua dedicação à causa da incorporação dos xavantes ao mundo civilizado, à cristandade e à nacionalidade brasileira, os missionários e, posteriormente, os agentes da política indigenista, demonstram a centralidade da cristianização do indígena para a imposição da ordem moderna à totalidade do território brasileiro, reduzindo os cada vez mais raros quistos de alteridade à lógica hegemônica do estado. Os viajantes que, como Hermano, percorriam o Brasil central como mistos de exploradores, aventureiros e conquistadores, participam desse projeto, especialmente à medida que, dotados do dom da palavra escrita, prontificam-se não apenas a viver a experiência da barbárie, mas também a reportá-la a um público sedentário, simultaneamente fascinado e atormentado pela imagem do estranho dentro da própria nação.

\footnotetext{
${ }^{86}$ Ibidem p. 268-9.

${ }^{87}$ Trata-se do padre francês Hippolyte Chovelon (1884-1966).

${ }^{88}$ NA SERRA do Roncador. A marcha da Bandeira Anhanguéra entre os chavantes. (Publicação feita á vista do archivo da Bandeira). Conclusão. O Estado de São Paulo, 22/07/1938, p. 9.
} 


\section{Apontamentos finais}

Em um dos episódios mais simbólicos do dilema vivido pelos exploradores na fronteira da civilização, em certo momento Hermano Ribeiro da Silva tece uma crítica aos indígenas, atribuindo a eles práticas próprias ao materialismo moderno, ou seja, hábitos internalizados que conduzem a uma "relação puramente 'utilitária' dos seres humanos entre si e com a natureza" e ao "envenenamento da vida social pelo dinheiro" territórios mais selvagens, despertava o interesse de visitantes brasileiros e estrangeiros, e uma das consequências disso é que os próprios indígenas enxergaram aí a oportunidade de valorização dos serviços prestados por eles como carregadores, guias e tradutores. Ao deixar a ilha do Bananal, o grupo de Hermano carece de montarias, sendo obrigado a realizar um revezamento entre aqueles capazes de caminhar. Esperava-se que os guias indígenas aceitassem contribuir com o sacrifício, mas eles frustram essas expectativas:

Propuz-lhes tambem a alternativa de marcha a pé, mas para isso exigiram compensações. A noção de estima e de reconhecimento não se agasalha nos seus espiritos como bem fundamental. Habitando as margens do Araguaia, os carajá adquiriram o vicio de mercantilizar todos os serviços prestados aos viandantes, condicionando os minimos trabalhos ao exclusivo interesse da paga. Os guias já ganharam objectos de valor para effectuar a excursão, como facões, roupas, cobertas e algum dinheiro; entretanto a precisão da emergencia lhes disperta a astucia, pela qual advinham [sic] agora a possibilidade de outros proventos. Combinamos todavia não nos cingir ás atrevidas imposições e desprezamos o concurso dos bugres relapsos..$^{90}$

Juízos como esses demonstram a duplicidade dos parâmetros utilizados pelo sertanista em seu exame do comportamento das populações nativas. Por um lado, sua cultura originária era tida como atrasada em termos evolucionistas. Esse atraso representaria, idealmente, maior afetividade, desinteresse e, em última instância, submissão voluntária aos desígnios dos brancos. Por outro lado, a aquisição de valores e comportamentos próprios dos ditos "civilizados", como a "mercantilização", é considerada espúria, pois assimilar costumes modernos não se traduz em uma forma de ascensão dos autóctones. Pelo contrário, à medida que sua trajetória parece convergir com uma prática em vigor na "civilização", como no caso em tela, passa a ser lida como degradação. A prévia condenação do trabalho indígena não remunerado, exercido

\footnotetext{
${ }^{89}$ LÖVY, Michael; SAYRE, Robert. Revolta e melancolia. O romantismo na contramão da modernidade. Tradução Guilherme João de Freitas Teixeira. Petrópolis: Vozes, 1995. p. 59.

${ }^{90}$ SILVA, 1935, op. cit., p. 281.
} 
com base na força, combina-se aqui a uma pressuposição de que relações de amizade conduziriam a uma forma de colaboração benéfica e gratuita, de maneira que a servidão não capitalista parece ser o comportamento esperado. Aparentemente, invertem-se os papeis do homem "moderno" e do "primitivo", aquele afetivo, esse racional.

O desconforto daí resultante é paralelo àquele experimentado pelo escritor quando se sente etnografado, submetido por um sertanejo a "uma saraivada de infindáveis perguntas querís [sic, por pueris] sobre as conquistas da grande industria civilizada." ${ }^{91} \mathrm{Em}$ ambas as situações, o intercâmbio cultural com os nativos e os sertanejos é desautorizado. Da mesma maneira, ele se mostra cético quanto às possibilidades de promoção social daquelas populações, em virtude de uma desigualdade intrínseca e de uma resistência aparentemente orgânica à modernidade. Mesmo quando pacificados, o potencial de sedentarização, trabalho e racionalização dos indígenas é, na maior parte das vezes, inteiramente negado. Ao invés disso, o encontro do viajante com a diferença cultural representada por eles produz um discurso normativo e pouco disposto à negociação, submetido à régua evolucionista. Os homens, assim como as terras do Brasil central, são, portanto, objetos de uma conquista a ser realizada por meio de provas de dedicação, vigor e tirocínio prestadas por sujeitos exógenos.

Artigo recebido para publicação em 05/08/2020

Artigo aprovado para publicação em 29/10/2020

${ }^{91}$ SILVA, 1936, op. cit. p. 193. 